International Review of Research in Open and Distributed Learning Volume 19, Number 1

February - 2018

\title{
Virtual School Startups: Founder Processes in American K-12 Public Virtual Schools
}

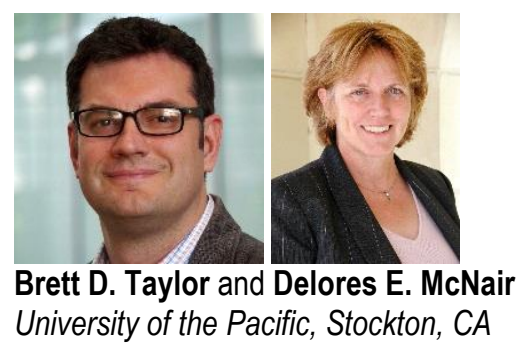

\begin{abstract}
Traditional school districts do not have a lot of experience with virtual schools and have lost students to state and charter virtual schools. To retain students and offer alternative learning opportunities, more public districts are starting their own virtual schools. This study was an examination of foundational processes at three California virtual schools in traditional school districts. An analysis of the findings revealed that sites perceived the establishing founder, preliminary research, district support, teacher and staff selection, financial evaluation, and curriculum decisions as keys to the founding process. The analysis also led to surprising conclusions, including the need for virtual schools to constantly change and adapt and the focus in this study of organizations over technology. The findings have implications for traditional districts starting virtual schools. The study also indicates that changes in policy could reduce the need for organizational adaptation among virtual schools in traditional school districts.
\end{abstract}

Keywords: virtual school, K-12 online learning, organizational structure, traditional public school districts, foundational processes

\section{Introduction}

Schools where all or most teaching and learning happens online are a specific category of called virtual schools (Watson, Murin, Vasha, Gemin, \& Rapp, 2011). These schools use the advantages of online learning to create holistic school organizations (Watson, Pape, Murin, Gemin, \& Vashaw, 2015). They differ from traditional schools, referred to as brick and mortar since students do not meet with teachers and other 
students in a physical space; most teaching, learning, and interaction occurs in an online space (Clark \& Berge, 2005; Moore \& Kearsley, 2012). Some virtual schools allow students to take all of their schooling through the online organization, a primarily North American phenomenon (Barbour, 2009).

Many of the earliest virtual schools in the United States were systems run independently by a state government, or were charter schools, run by independent organizations under special charter law. Statewide systems were run by state educational organizations, often receiving heavy funding from the state (Watson et al., 2011). Laws governing charter schools were developed to create flexibility for innovation not granted to traditional public schools. These governing laws allow charter schools to deliver curriculum more freely, escaping parts of stringent state and federal accountability (Ahn, 2011). Because traditional school districts were not granted the funding of statewide virtual schools or the flexibility of charter schools, they were late in starting their own virtual schools (Watson et al., 2011).

Many charter online schools are run by non-profit or for-profit organizations receiving public funds (Watson et al., 2011). Part of the purpose of the charter and school choice movement was to increase diversity competition with public schools and improve overall education (Lubienski, 2003). But in the case of virtual schools, there was little initial traditional school district competition (Watson, Winograd, \& Kalmon, 2004).

Additionally, virtual charter schools were even more successful in diminishing traditional public school populations than other charters, partially because virtual schools are free of the physical constrictions and boundaries of other schools (Waters, 2011). Because of this threat, traditional districts have moved to create their own virtual schools in order to keep students in their districts (Watson et al., 2011). This allows school districts to capture their own students and maintain the funding these students create for their district. Virtual schools also create an opportunity for traditional districts to be part of school choice recruitment and compete for students outside of their own district boundaries (Moore \& Kearsley, 2012).

Many traditional school districts are attempting to quickly start new virtual schools, but they may be unaware of the issues that influence founding an online school (Watson et al., 2011). Additionally, the average traditional school district is largely unprepared to deal with the unique circumstances of virtual schools (Ahn, 2011). Most online schools have been independent of district control or part of an independent online school district (Watson et al., 2011). Traditional school districts must navigate their relationship with dependent online schools differently than they do with their other schools and differently from other types of online schools.

A successful brick-and-mortar school organizational structure differs greatly from a successful virtual school organizational structure, yet many traditional districts founding new virtual schools often attempt attempting to function under a brick-and-mortar organizational model and encounter challenges (Archambault \& Crippen, 2009; McFarlane, 2011a; Reid, Aqui, \& Putney, 2009; Vrasidas, 2003). School districts attempting to start their own online schools need to understand how to adapt their organizational structure to create successful online schools to compete with other online school providers to effectively offer this alternative educational opportunity to students. 
The purpose of this study was to examine how traditional school districts create online schools. This study adds to the body of research on virtual schools by examining specifically the processes that American K-12 traditional public school districts start their own virtual schools.

\section{Description of Methodology}

This study used a multiple case study approach to analyze virtual school startup processes. Multiple case studies examine several similar or contrasting cases (Stake, 1995). The cases studied were three virtual schools within traditional public school districts. The selected criteria for this study's case selection were dependent virtual schools, or virtual schools governed by a traditional school district. The researcher selected dependent virtual schools in traditional school districts in California that were at least in their second operating year. This ensured that the school had enough time after opening to encounter and adapt to contingencies. Virtual schools selected also were schools that have offered a fully online option since their inception and had been created in the district using district teachers, not outsourced to outside online providers. Thus, this sample was selected from schools in the state that met the criteria established by these parameters of the study.

Data were collected through document analysis, interviews, and observations. The data collection followed specific protocol pertaining to three phases of each school's history: the foundational phase, the adaptation phase, and the current phase. Data were analyzed through a double coding cycle utilizing descriptive and pattern coding. The findings were validated through triangulation and member checking. Pseudonyms were used to protect the anonymity of the school, related locations, and human participants.

\section{Cases}

To help provide a context for the study, each case is described here; this allows the readers to develop a sense of the schools and their organizational cultures. All of the school sites and study participants are identified by pseudonyms.

Manchester. Manchester is a K-12 virtual school in southern California. Manchester District began their online school because they had seen research showing schools in other states were losing students to charter virtual schools. Additionally, the superintendent was very interested in starting a virtual program. The district began developing supplemental classes connected to the high schools. These courses were designed with original curriculum written and taught by district high school teachers working parttime on the supplemental program. The district coordinator who developed these programs was reluctantly directed by the superintendent to begin a full-time online school and serve as principal. The school began a year after the district had employed supplemental online programs and hired successful teachers from the part-time program full-time. The school started at a former elementary school and consisted of a staff of one principal, one administrative assistant, one technology coordinator, and one full-time teacher. After the first year, the school was transferred to a campus that housed three other alternative education programs and the principal was made the director of the entire alternative education campus. The school shared administrative and facility resources at this campus. After two years, the virtual school adopted a middle school program. After five years, the virtual school added an elementary component to create a 1- 
12 program, although the high school, middle school, and elementary programs all function differently. The school is in its sixth year of operation. The founding principal moved to the district office at the beginning of the year of the study as an assistant superintendent and then later left the district. A new principal was brought in from out of the district and had worked at the site for three months before this study began.

Branford. Branford is a virtual charter school in central California and is in its fourth year of operation. The Branford School began when a district media specialist who had been working with an online credit recovery program pushed the district to start a virtual charter school. The school initially began with high school teachers from the district who worked part-time and who created their own on-line curriculum and content. The school grew to nearly 100 students. After two years and some difficulties, the founding principal retired. Another director was hired who also oversaw the adult school and other alternative education programs. The district gave him a mandate to improve the virtual school or risk its closure. Another administrator who had been working with online content in an alternative education setting was hired to specifically oversee the virtual program. The new administration adopted a vendorbased curriculum they had used in the alternative education setting and started to hire full-time teachers. At first they hired one, added another, and hired part-time teachers as necessary. By 2014, in its fourth year in existence, the school had risen to 20 full-time teachers, three counselors, and an enrollment of 500 students.

Field Haven. Field Haven is a virtual school in northern California that at the time of the study was in in its fourth year. Three district office co-directors, the district director of curriculum and professional development, the district director of communications, and another district coordinator were the initial administrative founders of Field Haven. The first two elementary teachers worked at the district curriculum office with the district curriculum department to launch the school. Field Haven adopted a vendor curriculum platform and began with two programs, a K-8 program that used full-time teachers and a high school program that used part-time teachers. After the first year of start-up, the school was turned over to an administrator and a small administrative staff who also ran the alternative independent school on a separate site. The new administrator evaluated the school's data and concluded that the high school program had insurmountable enrollment and financial issues. After the second year, the administrator recommended to the district board that the high school program be discontinued and the board agreed. The K-8 program maintained three teachers and moved into two rooms on the campus of another elementary school, which allowed students the opportunity to receive face-to-face teaching as well. The school has enjoyed a small but steady enrollment over the past few years.

\section{Findings and Discussion}

Evaluating the multiple cases revealed common themes among foundational processes. This section relates those findings and further examines their meaning. Stakeholder quotes and narratives are included to give a context for the findings and to drive discussion about the perception of foundational processes. Additionally, surprising conclusions are revealed and implications of the findings and potential areas of further study are shared. 


\section{Foundational Processes}

The data revealed a varied list of foundational processes, which particpants at the sites identified as important for start-up and success (see Figure 1). From this data emerged some important findings from each process.

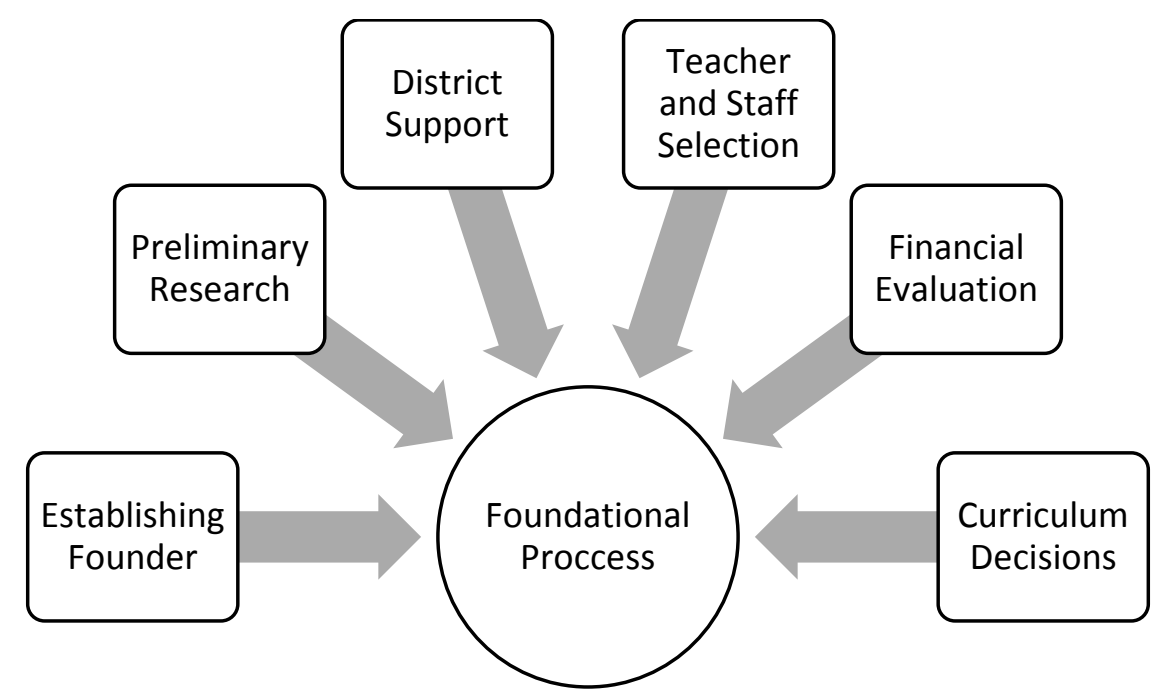

Figure 1. Identified foundational processes.

Establishing founder. Each school had an individual who led the process, but the source of initiation for each school differed greatly. Field Haven was initially a district creation, with three different district founders driving the foundational process and working with teachers in the first year before the school was handed off to a site administrator. These founders included the District Director of Curriculum and Professional Learning and the District Director of Communications, and another District Officer. Kelly, a founding teacher at Field Haven, explained:

The district wanted to start the program and it was the curriculum department that was kind of overseeing everything at the beginning, who did all the hiring, who sorted everything out. So we worked with the district office on the people that were on those departments or the people that were kind of our administrators.

Field Haven was the school most heavily driven by a district push, although the district involvement decreased significantly after the school's leadership moved to a separate administrator.

Branford's founding principal, Howard, was the source of the initial push for a virtual school in the district. Because of his interest in technology, he talked with district administrators for years until they allowed him to present some data to justify the need for a virtual school. Howard acknowledged that he often felt alone in the process and lacked the district support identified at the other two schools. He felt the district supported the virtual school, but no one at the district level had the expertise to work with him on the school's needs. He explained: 
The support systems from the district for the overall program really were dependent on me and not on anyone else. They didn't know how to support the school. They used traditional measures to see if we were being successful. You know, grades, the attendance, and those things that were traditionally [measured]. The statistics that nobody ever looked at was how many kids didn't drop out of school because of the online school? Those statistics were hard to [obtain]. I felt supported by the school board and the administrators as much as they could.

Manchester also had a strong founding principal, Patrick, but the initial push for the virtual school came from other district leadership. Patrick had built the supplementary program that allowed for high school students in the entire district to take online courses and remain at comprehensive schools. The district superintendent wanted him to move towards a completely virtual school and the founding principal initially resisted, then agreed. Patrick explained:

She kept on trying to pressure me to do it. I kept on saying, "I'm not interested. I don't want to do that." We finally came to an agreement that as long as we were going to maintain the activity on the supplemental side, and it was going to be a part of the work at the full-time site, that I would go ahead and do the full-time site, but [they] had to stay connected to each other.

While some district leadership wanted a virtual school, the founding principal and his staff did the actual work.

All sites had one founder who took the reins of the school. Because the districts were focused in many directions, a founder was seen as key to focusing effort on the virtual schools and pushing the school forward. Because of the unique nature of the virtual schools, a strong founder was key to the process.

Districts starting virtual schools should identify a strong founder who can gain the expertise needed to focus efforts on the virtual school. While district support was identified as helpful, sites saw the need for a strong founder to establish and lead virtual schools.

District support and commitment. Both Branford and Manchester identified their district's support of the virtual school as a key factor to survival and success. The initial support was noted as especially important as the schools were in an experimental development phase. Manchester teachers expressed that they could try new things because the district supported their efforts. John, the Branford learning director, explained that in the beginning it was important to have district support because there were not any data to support that what the virtual school was doing was working. The district supported the school and showed faith in the process before the data demonstrated student success. Branford administrators and teachers also revealed that the district support increased as schools were able to demonstrate success. Once the school began showing real success in increased enrollment and improved student achievement, the district was ready to offer even more support. Table 1 displays cascading quotes from staff at Branford and Manchester about district support. 
Table 1

Cascading Quotes about District Support

$\begin{array}{ll}\text { Participant } & \text { Quotation }\end{array}$

Karen,

Manchester Teacher

Patrick,

Founding Manchester

Director

David,

Branford Director
I heard the word pioneer like 17 times in meetings, and the superintendent would come and sit with us, and say, "You're blazing the trail. No one's ever done this. Of course, it's going to be difficult." There was a lot of support. We weren't pressured to figure it out, necessarily. It was always OK to fail. We were allowed to explore, and try new things. In many ways, that was freedom most of us hadn't had before. We did a lot of good work.

There had to be a district commitment to walking forward a program that had no students with the belief that students were going to come, if you billed that they will come. We absolutely had the commitment. The district has been consistently supportive of the online program, in terms of dedicating dollars from the general fund to support it.

Once we proved ourselves, once they saw that we were serious about running the school, putting our guts into the school, and that we were serious about and we were passionate about, and once the numbers stayed, they gave us whatever we asked for. "You need more rooms? Take more rooms." Once they saw the things are moving forward tremendously, they have been absolutely incredibly supportive.

Our district said, "[John] we're going to support you." Then I started making money. Then they really support you.
John,

Branford Learning Director

Participants defined support as district confidence and trust, monetary support, facilities, and staffing. The monetary support was frequently identified when administrators talked about the economic downturn that affected California school budgets over the preceding several years. Administrators emphasized that the district support to continue to fund their virtual schools when many viewed the programs as supplementary or excessive was important to the schools' survival.

Preliminary research. All three districts were involved in some research that either helped them determine the need for a virtual school or helped them determine the goals and direction of their virtual school. Howard, Branford's founding principal, reported that when the superintendent requested data to show the need for a virtual school, the district found that 500 students were leaving the district a year from expulsions and other reasons. Once these data surfaced, the founder had more district support in starting the virtual charter.

Manchester also reported data that revealed the potential loss of district average daily attendance (ADA), which determines district funding in the state of California. However, the data Manchester reviewed were not from their district but from other states where online schools had grown over the years. The data 
reviewed from Florida, Ohio, North Carolina, and Kentucky that revealed districts in these states were losing ADA student enrollment to outside virtual schools. While these data were never supported at Manchester, they did motivate the beginning of the virtual school.

In addition to reviewing the data from other states to determine the need for a virtual school, Manchester also looked to other states that had already embarked on virtual schools to identify best practices. District and school administrators went to Florida, Ohio, and Kentucky to learn from others' successes and mistakes. This initial research helped administrators make decisions about how to launch the new virtual school.

Field Haven's research process focused more closely on the community. The district launched fishbowl observations with community stakeholders including parents and teachers to guide its decision-making process. These observations helped the district identify what parents were looking for in a virtual school and how teachers and a vendor system could meet these needs. District directors were heavily involved with parent and community meetings throughout the launch process and Field Haven founding teachers talked to the researcher about the launch period as a time when they felt closely connected both to the district and to the community.

While the sites each undertook different forms of preliminary research, they all used research to make foundational decisions. The importance of some of this foundational research can be questioned since some of the sites eventually changed their direction. In other cases the research did not bear true, as was the case with Manchester's research of other states losing ADA. Even when initial data did not drive the virtual schools past their foundational stages, the fact that the sites conducted and analyzed research did prove important to their future adaptation. The culture of research they developed allowed them to continue to identify needs and change course when necessary.

Teacher and staff selection. All sites identified the ability to freely hire teachers and staff as important. During the hiring process, all three districts gave their sites freedom to select teachers, instead of placing teachers mandatorily. All three sites had a strong process for hiring teachers internally. Manchester built their hiring from teachers who had shown success in the supplemental online program. These teachers were chosen from a group who had undergone a voluntary pilot training program. Branford hired their first full-time teachers from teachers who had been successful in their independent study program. Field Haven created a hiring process to ensure dedicated teachers would lead the program.

The strongest support of the teachers at the sites can be found in the words of their administrators. Paul, the Field Haven administrator, expressed, "What I can guarantee you with our program is that our teachers are highly qualified. The students are going to receive the best curricular expert possible." John, the Branford learning director, shared, "You walk through those rooms back there. They've [the teachers] got the same passion I've got." The administrators demonstrated confidence in their teachers' abilities and they said that being able to select the teachers from their program made a huge difference in the quality of their school.

Teacher motivation can be an issue if teachers are placed at a site instead of selecting to be there, but that might especially be true when the site requires a new skill set like virtual schools do. Additionally, the sites 
identified processes for training and evaluating online teachers before hiring them. This allowed the sites to evaluate teachers for online teaching skill set before hiring them. Districts starting virtual schools need to allow virtual schools to hire new staff who want to be at the site and who are identified as having a skill set valuable to online teaching.

Financial evaluation. Financial evaluations at the sites analyzed how the districts could financially support the schools. Sites were supported even in the wake of district budget cuts. Virtual schools in traditional school districts need to receive sufficient financial support. If virtual schools are seen as "extra" programs unworthy of the same financial support as traditional brick and mortar schools or as ways to generate ADA or save districts money, the virtual schools will not receive sufficient support for success. While the virtual school funding structure differs from traditional brick and mortar schools, virtual schools still require a great deal of funding to be successful.

Curriculum decisions. While this was identified as an important foundational process, the nature of the curriculum mattered less than the site's confidence in it. Of the three sites, one used a vendor curriculum, one used a self-created curriculum, and one had switched from a self-created curriculum to a vendor curriculum. Many online curriculums have been successfully adopted. Sites and districts can focus a lot of time and energy trying to find the right one. But at the sites studied, the success of the curriculum depended as much on the implementation of the curriculum as anything. Some of the sites changed the way the curriculum was delivered during the lifetime of the school, so adaptation features discussed below may be as important as the initial implementation. Manchester created their own curriculum and it was a critical part of the school. Table 2 shows cascading quotes from several Manchester staff members about developing curriculum as a foundational process.

Table 2

Cascading Quotes about Developing Curriculum as a Foundation Process at Manchester

Participant Quotation

Richard,
Manchester
Founding Staff Developer

Patrick, Manchester Founding Principal
We decided with the same book, the same curriculum, and the same pay scale at that point because we were all on district pacing at that point. That's kind of what they started. We looked at vendor products. We created some courses. We would try and break them up, arrange them to meet our pacing, our textbooks and so on. A lot of the courses were either created by the teachers or modified by the teachers to meet those district needs. There's very few vendor-created products that worked for that. We couldn't find any English classes that met our needs. We took the best of whatever we could and tried to cobble together.

Because we wanted to change teaching and learning, we didn't buy a canned curriculum. We built our curriculum to match the pacing. Integrated the same teachers, same textbooks, same assessments, that we were really trying to create a digital version of our particular curricular program 
Don, Manchester Teacher here in the district. Because we did it that way, it was a completely scalable solution.

When you think about, my kids, in my regular classes, that I developed are going more in-depth than the [vendorcreated] course. That's because I've always created curriculum and designed curriculum. We've had people come back and talk to us from INACOL. They were talking about how our courses are so far ahead of what most schools are doing online.

\section{Surprising Conclusions}

In conducting this study, the focus was examining the foundational processes school identified. In analyzing these findings, some conclusions developed that were contrary to some of the expected outcomes. This section presents these conclusions and includes discussion of why these unexpected conclusions exist and what they mean to the context of the study.

Site-district relationships. The relationship between the district and the school sites was an identified contingency and area of adaptation but not to the degree expected. For the most part, the virtual schools reviewed here were self-sustaining entities. They received funding and resources through the district as did other schools, but in some ways they functioned more independently than the other schools. One possible reason for this difference is that the districts were built to serve traditional brick and mortar school sites. Expertise at the district level was generally not suited to meet the needs of the virtual schools. The virtual schools held the expertise; thus, the districts allowed them to act more independently than the other school sites. Each of the sites identified a district ally, someone with power in the district office who believed in the program and wanted it to succeed. Whether this was the superintendent or a director, in almost all cases the support was not at a decision-making level. The district-level leaders deferred to the sites on most decisions. The exception to this rule was Field Haven in the foundational stages and first year in operation when a district-level position was making decisions for the school. But even her expertise limitations were discovered in the area of the high school and she eventually deferred to a site administrator.

Participants indicated that financial support, resources, and staffing were the most desired types of support they sought from the district-level leaders. All three sites identified their support from the district. The strongest identification for support came from the site that had received the most direct administrative and counseling staffing, Branford. But all three sites identified the need for more support. The feeling that the districts did not fully understand the virtual schools was also prevalent, and several participants argued that the calculations the district used to determine staffing and resources were based on the needs of traditional brick and mortar schools and that these districts did not understand the calculations did not apply to the needs of the virtual schools.

The structure of traditional school district calls for adaptation unique to virtual schools. The resources of a traditional school district can allow for support not being offered to independent virtual schools, but based on the findings from this study, there is also the danger that virtual schools will be forgotten, ignored, or misunderstood. In addition, the data from this study revealed the perceived need for districts to fully fund new virtual schools. The virtual schools cannot be seen as a money-saving measure and if anything, the 
findings revealed that virtual schools could be more costly than traditional schools. Additionally, virtual school officials have to communicate their needs to districts through leaders who can articulate the unique circumstances of virtual schools and educate district officials on the advantages and trials of such schools. District administrators that hope to start virtual schools or who have recently started virtual schools need to ensure that expertise is developed not only at the site level but also at the district level so that appropriate support can be provided.

Need for change and adaptation. Each of the sites changed and adapted their organizational structures had changed and adapted as the school developed. Additionally, many of their goals and outcomes also changed. Change is a necessary part of any organization and any school, but the necessity for change seemed accelerated at these sites. The rate of change for these virtual schools was incredibly high for schools that had been in existence between four and six years. For example, Branford changed their entire curriculum, staffing, and leadership model after two years and Field Haven dropped their high school program after two years. Because virtual schools are a relatively new phenomenon and because each of these sites was a new undertaking for these traditional school districts, change, and adaptation were prevalent. Site leaders were learning how to implement new systems as laws and resources changed around them.

In the initial stages of this study, I anticipated that perhaps the findings might lead to a common list of methods and techniques that could help virtual schools adapt to the difficulties they would face or a best practices list because of the common context of virtual schools in traditional school districts. While these findings were manifest, the level of specificity of these techniques is not as high as originally expected. Instead, the sites studied revealed different ways of adapting to various issues. More important than the specific strategies employed was the ability of each site to adapt and change as needed in response to its specific context and experiences. Whether these techniques included a strictly structure organizational hierarchy as in the case of Branford, or a more open organizational system like Manchester, the actual structure used was less important than whether the structure allowed for adaptation and change.

Each of the sites studied demonstrated the ability to make large structural and procedural changes. Branford changed its entire curriculum, staffing structure, and administrative leadership after the first two years. Field Haven dropped half of its program. Manchester moved campuses, adapted to an alternative school structure, and added multiple grade levels. This level of structural change in such a short time is uncommon at most traditional brick and mortar schools, but among virtual schools this ability appears to be a necessity to adapt to an ever-changing system and to bridge the gap between the virtual site and the traditional school district.

Using mandated structures to advantage. Because virtual schools are part of a larger school district that must make decisions for the entire system, some systems were forced upon the case sites. This frequently happened with campus space, administrative staff, and office staff and resources. However, although these new structures were an identified contingency, sites found a way to use these structures to their advantage. Additionally, when sites were forced to take on other programs like the supplemental program at Manchester or the credit recovery program at Branford, they bolstered their virtual schools by using the resources of these added programs. 
Organizations over context. McFarlane (2011a; 2011b) theorized that online schools require a unique organizational structure from brick and mortar schools. Because of these findings, I expected that the findings of this study would reveal adaptation strategies unique to virtual schools. While the study revealed accelerated change process for the virtual schools studied, most of the findings revealed successful adaptation techniques evident in many traditional schools, and even in many other types of organizations.

In other words, organizational strategies that work for virtual schools can work for all organizations and strategies that work for all organizations can work for virtual schools. This is an important finding because data revealed that district officials felt they could take shortcuts or invest less in virtual schools. This study revealed that the kind of organizational features that would create success in any school are equally necessary in virtual schools. The context shifts the make-up of what these features look like at virtual schools, but features such as district support, direct administrative leadership structures, and strong teachers can be credited as positive to any school site. Districts need to recognize that building a virtual school will take the same amount of effort and resources as sustaining a brick and mortar site, if not more.

The other surprise with this study was the lack of focus on technology. Because the topic involved virtual schools, it was reasonable to assume that technology would be a major focus of the initiative to develop a virtual school. But as shared by Roger, the principal at Manchester, the people and organizational processes are more important than the technological processes. "I think the technology part is probably the least interesting. [That] aspect is really not the hard part."

Roger's observation demonstrates what might be the most surprising and important finding of this study. The findings suggest that the most important features of these virtual schools were a strong organizational structure, effective leadership, and support from the district, while participants identified anything pertaining to technology or the online platform as secondary in importance. These findings suggest that the term virtual school needs to have a greater emphasis on the school side than the online side. Online is a system of educational delivery, however, the features of what makes a good school were more about organizational systems than technological platforms at these virtual schools.

\section{Implications}

Because virtual schools are a unique context for traditional districts, districts must develop structures that address this context. The findings indicated that these contextual processes were well defined, though not yet streamlined to the circumstances of virtual schools. Districts must study their local accreditation, enrollment, and funding processes and structures.

The findings also revealed that virtual schools that had strong systems planning, management, and leadership dealt with fewer problems and obstacles than other schools who identified as struggling in those areas. In other words, systems planning, management, and leadership are strong indicators of initial and long-term stability in a virtual schools. Therefore, districts that are starting virtual schools need to create direct and defined leadership at sites, financially support the virtual schools, and hire dedicated full-time teacher leaders to avoid some of the setbacks that some of the sites studied encountered.

Another finding suggested that virtual schools studied needed to be adaptable in the process of operation. In other words, while a well-developed plan was helpful, the need to abandon parts of that plan and move 
in a different direction was identified as necessary to adapt to unforeseen contingencies, especially in the changing landscape on virtual school policy. These identified strategies could benefit traditional virtual schools in adapting to the unforeseen contingencies they will encounter. Additionally, a focus on these features could be beneficial to any schools or organizations facing unforeseen obstacles.

The findings of this study inform traditional school districts that creating and operating a virtual school requires a strong organizational structure, effective leadership, and support from the district. In the three cases studied, the organizational structure, leadership, and district support were more important to the success of the schools than anything pertaining to technology or the online platform. Because virtual schools use a unique online platform and require technology, these tend to be areas of focus by administrators and researchers. However, the findings from this study imply that more focus needs to be devoted to the organizational features of a virtual school in order to ensure success. Districts starting virtual schools need to ensure that these organizational factors are addressed instead of getting lost in the online and technological delivery systems.

While this study identified unique features in this process that pertain to virtual schools, this formula for success is not limited to virtual school. As traditional districts strive to design successful school, the virtual school must be seen as a unique but equal organization. Though the techniques may differ, the principles that will ultimately define success are similar to the traditional brick and mortar school. There cannot be short cuts.

Aside from informing leaders of traditional districts and virtual schools, the findings of this study are also relevant to policy makers. The study found that data relating to successful virtual school startup had less to do with the technology or curriculum of virtual school than it did with state policy and accreditation processes which not been adapted to the context of virtual schools. These issues could be eliminated or at least made easier to navigate if the legislators in California would acknowledge the difference in enrollment and attendance structures between virtual schools and brick and mortar schools. Legislators could design policy unique to virtual schools that accepted these structures instead of punishing virtual schools for adopting them. Additionally, accreditation boards could design processes that acknowledge the unique structures in virtual schools and utilize advisories with experienced virtual educators. The accreditation process would then educate the virtual schools, instead of the schools under review having to educate the advisory team.

\section{Areas for Further Study}

The cases selected were sufficient for the purposes of this study and the data did begin to saturate after the third school data was collected. However, examining additional cases with differing circumstances (rural environment, blended environment, etc.) could have revealed processes not identified in this study. Also, this study was only focused on virtual schools in traditional school districts. While more research exists on statewide and charter virtual schools, it does not focus on contingencies of virtual schools or adaptation features. Additional studies that examined the organizational structures of different kinds of virtual schools may provide findings about which adaptation features are beneficial in different kinds of virtual schools, or if they differ at all. 
The cases selected for this study were all California virtual schools. While this yielded sufficient data on startup processes in California virtual schools, study of additional sites outside of the state could reveal additional strategies and obstacles. Additional studies could examine context inherent contingencies in other states. These studies could prove beneficial to identifying state policy that is most conducive for traditional school districts creating virtual schools and could have an impact on policy throughout the country.

All of the three schools studied moved away during their history from a fully online model to a blended model, one that allowed for some online interaction between teachers and students and some face-to-face interaction between teachers and students. Manchester moved toward face-to-face the most of the three sites, but all of the sites could be identified somewhere on the spectrum of blended learning. Online learning is moving more toward blended models and more research is needed to identify the impact of this new learning, as well as what are the features of successful blended models.

Additionally, one of the findings from this study that was not explored in depth was the lack of impact that technology had on the organizational structure at the sites studied. There exists research on the impact of technology on the curriculum of virtual schools, but further research on technology and virtual school structures. Such research could help answer why a correlation was not identified in this study and could also reveal untapped technological features that have not been used at the sites studied.

\section{References}

Ahn, J. (2011). Policy, technology, and practice in cyber charter schools: Framing the issues. Teachers College Record, 113, 1-26.

Archambault, L., \& Crippen, K. (2009). K-12 distance educators at work: Who's teaching online across the United States. Journal of Research on Technology in Education, 41, 363-391.

Barbour, M. K. (2009). Today's student and online schooling: The reality, the challenges, the promise. Journal of Distance Learning, 13(1), 5-25.

Clark, T., \& Berge, Z.L. (2005). Perspectives on online schools. In Z. L. Berge \& T. Clark (Eds.), Online schools: Planning for success (pp. 9-19). New York, NY: Teachers College Press.

Lubienski, C. (2003). Innovation in education markets: Theory and evidence on the impact of competition and choice in charter schools. American Educational Research Journal, 40, 395-443.

McFarlane, D. A. (2011a). A comparison of organizational structure and pedagogical approach: Online versus face-to-face. The Journal of Educators Online, 8, 1-44. 
McFarlane, D. A. (2011b). Are there differences in the organizational structure and pedagogical approach of online and brick-and-mortar schools? Journal of Multidisciplinary Research, 3, 83-98.

Moore, M.G., \& Kearsley, G. (2012). Distance education: A systems view of online learning. Belmont, CA: Wadsworth.

Reid, K. M., Aqui, Y., \& Putney, L.G. (2009). Evaluation of an evolving online high school. Educational Media International, 46, 281-294.

Stake, R. E. (1995). The art of case study research. Thousand Oaks, CA: Sage.

Vrasidas, C. (2003). The design, development, and implementation of LUDA Online High School. Computers in the Schools, 20, 15-25.

Waters, J. K. (2011). Competing for the online student. Technological Horizons in Education Journal, 38, 28-30.

Watson, J., Murin, A., Vasha, L., Gemin, B., \&, Rapp, C. (2011). Keeping pace with K-12 online learning: An annual review of policy and practice. Durango, CO:Evergreen Education Group.

Watson, J., Pape L., Murin, A., Gemin, B., \& Vashaw, L. (2015). Keeping pace with K-12 Digital learning: An annual review of policy and practice, 11. Durango, CO: Evergreen Education Group.

Watson, J. F., Winograd, K., \& Kalmon, S. (2004). Keeping pace with K-12 online learning: A snapshot of state-level policy and practice. Naperville, IL: Learning Point.

\section{Athabasca}

University

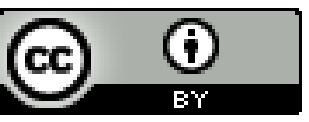

